\title{
Isolated Emphysematous Myocardial Abscess without Infective Endocarditis
}

\author{
Jino Park ${ }^{1}$, Sang-Hoon Seol ${ }^{1}$, Yeo-Jeong Song ${ }^{1}$, Seunghwan Kim ${ }^{1}$, Dong-Kie Kim ${ }^{1}$, Ki-Hun \\ $\mathrm{Kim}^{1}$, Doo-Il Kim ${ }^{1}$, and Bong Soo Park ${ }^{1}$ \\ ${ }^{1}$ Inje University Haeundae Paik Hospital
}

May 31, 2021

\begin{abstract}
A myocardial abscess is a rare and fatal disease, which is known to be challenging to diagnose, especially in case of isolated one without endocarditis. We present a case of emphysematous myocardial abscess detected by computed tomography, and echocardiography, and confirmed by surgery.

Isolated Emphysematous Myocardial Abscess without Infective Endocarditis

Jino Park ${ }^{1}$, Sang-Hoon Seol ${ }^{1}$, Yeo-Jeong Song ${ }^{1}$, Seunghwan Kim ${ }^{1}$, Dong-Kie Kim ${ }^{1}$,

Ki-Hun Kim ${ }^{1}$, Doo-Il Kim ${ }^{1}$, and Bong Soo Park ${ }^{2}$

${ }^{1}$ Division of Cardiology, ${ }^{2}$ Division of Nephrology, Department of Internal medicine

Haeundae Paik Hospital, University of Inje College of Medicine, Busan, Korea
\end{abstract}

\section{Corresponding author}

Sang-Hoon Seol, MD, PhD, Division of Cardiology, Department of Internal Medicine, Inje University, Haeundae Paik Hospital 875, Haeun-daero, Haeundae-gu, 48108, Busan, Republic of Korea Tel: +82-51-797-3010, Fax: 82-51-797-3009 E-mail:hacemed@hanmail.net

Disclosures: None.

Funding : None

Acknowledgment : No relevant acknowledgments.

Author contribution

JP: collected the information, edited figure and videos, and drafted the manuscript, SHS: designed the project and supervised the writing the manuscript, YJS: performed transesophageal echocardiography and described findings, SK, DKK, KHK, DIK: discussed the results and advised about the case, BSP: offered patient's clinical information. All authors read and approved the final manuscript.

\section{Key clinical message}

Diagnosis of myocardial abscess without endocarditis is challenging, and a high index of clinical suspicion is fundamental for diagnosis. It should never be ruled out before TEE. And CT could be a helpful modality in case of emphysematous morphology.

\section{Abstract}


A myocardial abscess is a rare and fatal disease, which is known to be challenging to diagnose, especially in case of isolated one without endocarditis. We present a case of emphysematous myocardial abscess detected by computed tomography, and echocardiography, and confirmed by surgery.

Keywords: emphysematous, myocardial abscess, Escherichia coli

\section{Case presentation}

An 81-year-old woman presented with dyspnea and fever. Physical examination, laboratory study, and chest x-ray indicated sepsis and heart failure. Transthoracic echocardiography showed no abnormality, but computed tomography (CT) demonstrated abnormal air bubbles with low attenuated lesions surrounding the mitral annulus (Figure 1). Transesophageal echocardiography (TEE) revealed a round, echo-free lesion in the lateral myocardial wall, and a moderate amount of pericardial effusion (Video S1, S2). During the surgery, an abscess pocket was exposed on the posterolateral wall of the left ventricle (Video S3). It was incised and drained.

A myocardial abscess has been generally diagnosed during autopsies or surgeries due to diagnostic difficulty and clinical lethality. ${ }^{1}$ Prompt diagnosis facilitates timely surgical intervention, and it is crucial for prognosis. ${ }^{2}$ If myocardial abscess exhibits emphysematous morphology, CT may play an important role in diagnosis, and if there is any possibility of myocardial abscess, it should never be ruled out before TEE.

\section{References}

1. Abdul-Waheed M, Yousuf MA, Schneeberger EW, et al. A rare case of Klebsiella pneumoniae myocardial abscess. The Journal of thoracic and cardiovascular surgery . Mar 2010;139(3):e34-5. doi:10.1016/j.jtcvs.2008.07.056

2. Chakrabarti J. Diagnostic evaluation of myocardial abscesses. A new look at an old problem. International journal of cardiology . Dec 1995;52(3):189-96. doi:10.1016/0167-5273(95)02484-0

\section{Figure legends}

Figure 1. Contrast-enhanced chest computed tomography image revealing abnormal air bubbles with low attenuated lesion (arrows) surrounding the calcified mitral valve annulus (arrowhead)

Video S1. Transesophageal echocardiography revealed echo free lesion in the lateral wall measuring $1.0 \mathrm{x}$ $0.6 \mathrm{~cm}$.

Video S2. Transesophageal echocardiography revealed moderate amount of pericardial effusion with plenty of fibrinous strands surrounding the heart.

Video S3. During the surgery, the abscess pocket was exposed on the lateral wall of the left ventricle. The abscess was incised and drained. There was no evidence of endocarditis.

Figure and videos

Figure 1. 


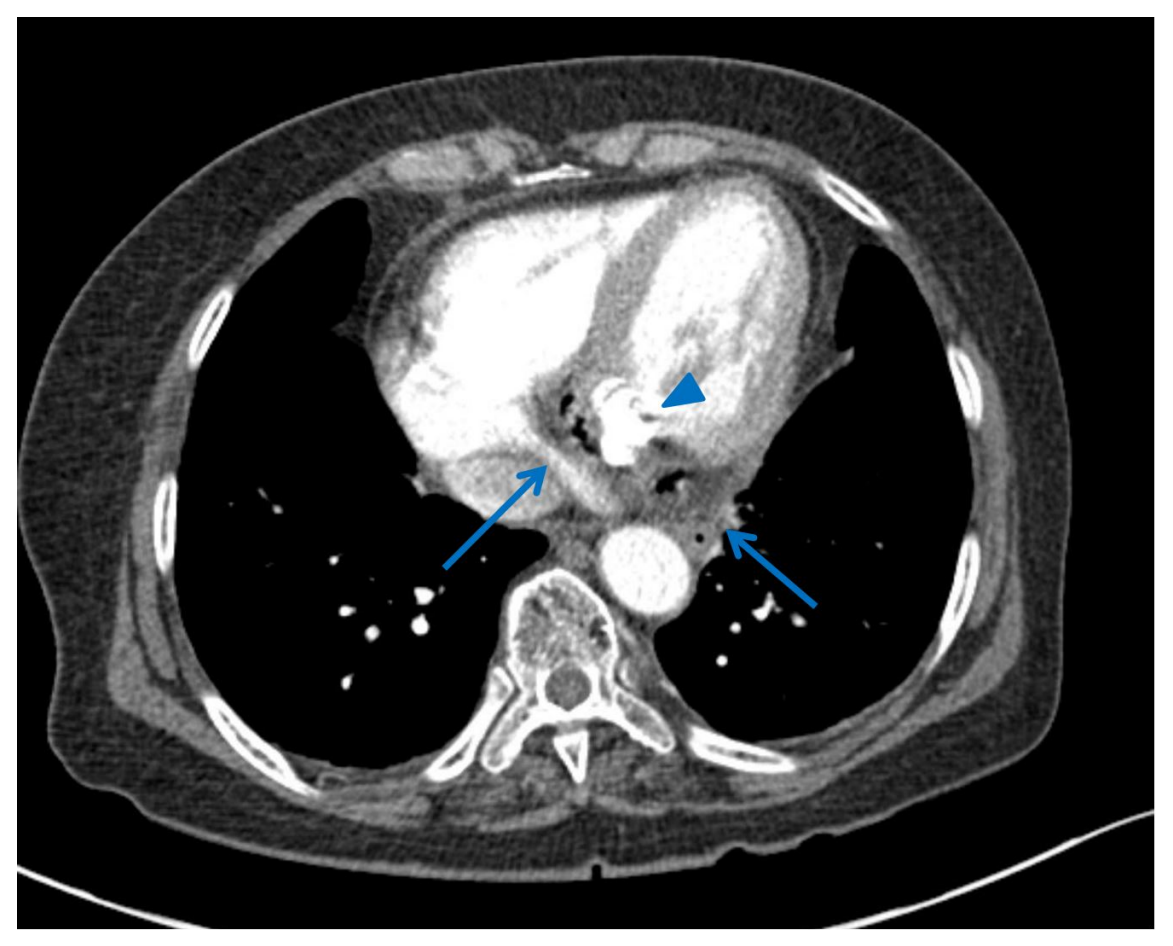

Video S1.

Video S2.

Video S3.

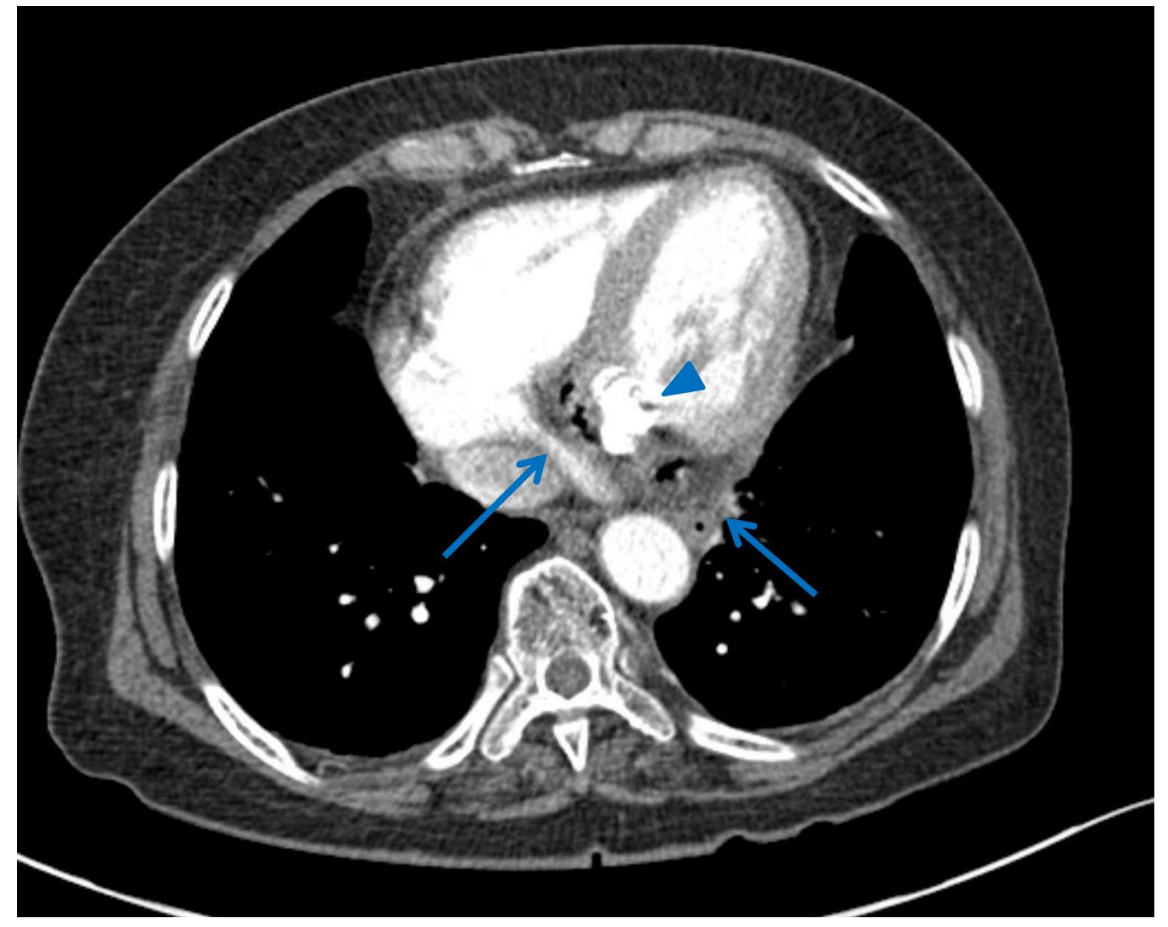




\section{Hosted file}

Video S1.mov available at https://authorea.com/users/417119/articles/524334-isolatedemphysematous-myocardial-abscess-without-infective-endocarditis

\section{Hosted file}

Video S2.mov available at https://authorea.com/users/417119/articles/524334-isolatedemphysematous-myocardial-abscess-without-infective-endocarditis

\section{Hosted file}

Video S3.avi available at https://authorea.com/users/417119/articles/524334-isolatedemphysematous-myocardial-abscess-without-infective-endocarditis 